\title{
THE EFFICACY OF EPIDURAL STEROID INJECTIONS IN THE MANAGEMENT OF PATIENTS WITH LUMBOSACRAL DEGENERATIVE SPINE DISEASES
}

\author{
Ode M. B', Taiwo F. $O^{2}$, Amupitan I3, Onoja A. $A^{4}$, Mancha D. G5, Ode G. N6, Nkinyam G. $Y^{7}$
}

${ }_{1}$ Senior Lecturer/Consultant, Department of Orthopaedics, University of Jos/Jos University Teaching Hospital, Plateau State, Nigeria. ${ }^{2}$ Consultant Orthopaedic Surgeon, Department of Orthopaedics, Jos University Teaching Hospital, Plateau State, Nigeria. 3 Senior Lecturer/Consultant, Department of Orthopaedics, University of Jos/Jos University Teaching Hospital, Plateau State, Nigeria. ${ }^{4}$ Consultant Anaesthesiologist, Department of Anaesthesiology, Jos University Teaching Hospital, Plateau State, Nigeria.

${ }_{5}^{5}$ Lecturer/Consultant, Department of Orthopaedics, University of Jos/Jos University Teaching Hospital, Plateau State, Nigeria.

${ }^{6}$ Public Health Physician, Jos University Teaching Hospital, Plateau State, Nigeria.

${ }^{7}$ Chief Resident, Department of Orthopaedics, Jos University Teaching Hospital, Plateau State, Nigeria.

\section{BACKGROUND}

ABSTRACT

Degenerative diseases of the lumbosacral region are becoming a more frequent presentation to the clinician, particularly with the increasing ageing population worldwide. These conditions result in impingement of the nerve roots and inflammation, causing radiculopathy along the course of the affected nerve root. Epidural steroid injections are commonly employed to alleviate the radiculopathy when the use of conservative methods of treatment have failed.

The objective of the study was to determine the efficacy of this treatment modality in our setting.

\section{MATERIALS AND METHODS}

This study was an observational study carried out at the Jos University Teaching Hospital, Nigeria. Patients who had epidural steroids within one-year period (July 2016 - June 2017), who were being managed for degenerative spine disease of the lumbosacral region were included in the study. The data was obtained from the case records of the patients. Epidural steroids were administered under sterile conditions. $80 \mathrm{mg}$ of Methylprednisolone was used with $3 \mathrm{~mL}$ of $1 \%$ lignocaine. This was administered via the interlaminar route to the epidural space. The patients' responses were assessed using the numeric pain scale (11-point scale from 10 to 0). Data was analysed using Statistical Package for Social Sciences (SPSS). Pain before the procedure, pain after the procedure and the pain differential on the scale were assessed as well as complications. The paired t-test was used to analyse the mean pain scores at $95 \%$ confidence interval and a p-value $<0.05$ was considered statistically significant.

\section{RESULTS}

A total of 34 patients were involved in the study. 11 males and 23 females with a male: female ratio of 1: 2.1. The ages of the patients ranged from 20 to 80 years with a mean age of 57.2. The pathologies were disc degeneration and herniation 21 (61.8\%), degenerative spondylolisthesis 6 (17.5\%), spinal canal stenosis $4(11.8 \%)$ and prolapsed intervertebral disc $3(8.8 \%)$. The mean score before the procedure was $8.8 \pm 0.81 ; 6(17.6 \%)$ patients scored 10, $17(50 \%)$ scored $9,9(26.5 \%)$ scored 8 and 2 (5.9\%) scored 7. Mean pain scores after the procedure was $2.2 \pm 1.34 ; 14(41.2 \%)$ patients scored 1, $9(26.5 \%)$ scored 2, $5(14.7 \%)$ scored $3,4(11.8 \%)$ scored 4 and 1 each $(2.9 \%)$ scored 5 and $6 ; 31(85.3 \%)$ patients had a reduction by $50 \%$ or more in their pain scores. A statistically significant difference ( $\mathrm{t}=25.09 ; \mathrm{p}<0.000$ at $95 \%$ confidence interval) was observed between the mean pain scores before and after epidural steroid injection.

\section{CONCLUSION}

Epidural steroid injections are a safe and effective method of treating patients with radiculopathy from lumbosacral degenerative spine diseases.

\section{KEY WORDS}

Epidural, Steroid, Injection, Lumbosacral, Spine.

HOW TO CITE THIS ARTICLE: Ode MB, Taiwo FO, Amupitan I, et al. The efficacy of epidural steroid injections in the management of patients with lumbosacral degenerative spine diseases. J. Evolution Med. Dent. Sci. 2018;7(28):3216-3219, D0I: $10.14260 /$ jemds/2018/723

'Financial or Other Competing Interest': None.

Submission 20-05-2018, Peer Review 25-06-2018,

Acceptance 01-07-2018, Published 09-07-2018.

Corresponding Author:

Dr. Ode M. B,

Department of Orthopaedics and Trauma,

Jos University Teaching Hospital,

PMB-2076, Jos, Plateau State,

Nigeria-930001.

E-mail: odemb2014@gmail.com

DOI: $10.14260 /$ jemds $/ 2018 / 723$

\section{(c) $($ ) $\$$}

\section{BACKGROUND}

Degenerative spine diseases are a group of degenerative conditions in the lumbosacral region ranging from intervertebral disc degeneration, which can be single or multiple and may be associated with disc herniation into the spinal canal, spinal canal stenosis, degenerative spondylolisthesis, hypertrophy of the ligamentum flavum, facet joint arthritis and degenerative lumbosacral scoliosis amongst others.(1) These conditions may be associated with instability of the lumbosacral spine. The effects of these pathologies is that they result in an impingement of the neurological structures with resultant inflammation.(2) The individuals so affected present with radiculopathies along the 
distribution of the nerves. Pain is the most worrisome presentation and can be debilitating in some instances. Spinal claudication and a gradual loss in motor and sensory functions depending on the degree and extent of the impingement may also be present.

These conditions affect typically people in the $5^{\text {th }}$ decade of life and above increasing in frequency as age progressed. $(3,4)$ With improved health care modalities, there is an increasing ageing population in Nigeria and the world generally. More people in this age bracket result in an increased frequency of these degenerative conditions presenting to the clinician. Many modalities are employed in the treatment of these conditions and they include postural modification, physiotherapy, drug management, epidural steroids and surgical interventions. $(1,3,5,6)$ These treatment options are administered alone or in combination, with the goal of reducing or eliminating the pain, other radicular symptoms and improving function. Epidural steroid injections are used with the aim of reducing the inflammation of the neural structures which may serve to reduce the oedema around the nerves and reduce the degree of impingement on them.(7-12) This modality of treatment is usually used when other conservative methods of treatment have yielded suboptimal results or in combination with other non-operative modalities.(13,14) In some instances, steroid injections may be used post-operatively in patients with persistent radicular pain following surgery.(15,16) It can also be employed while awaiting surgical procedures to relieve pain and ameliorate other symptoms in Nigeria where the availability of spine surgical services is not as wide spread as desired and with the high cost of these services which may be out of reach for quite a number of indigent patients, epidural steroids can be employed while awaiting surgery and is also used to relieve symptomatology in combination with other non-operative treatment procedures in patients who may not be fit to undergo surgery. The objective of the study was to determine the efficacy of this treatment modality in our setting.

\section{MATERIALS AND METHODS}

This study was an observational study carried out at the Jos University Teaching Hospital, Nigeria. Patients who had epidural steroids within one-year period (July 2016 - June 2017) who were being managed for degenerative spine disease of the lumbosacral region were included in the study. The data was obtained from the case records of the patients. Epidural steroids were administered under sterile conditions. $80 \mathrm{mg}$ of Methylprednisolone was used with $3 \mathrm{~mL}$ of $1 \%$ lignocaine. This was administered via the interlaminar route to the epidural space. The patients' responses were assessed using the numeric pain scale (11-point scale from 10 to 0 ). Data was analysed using Statistical Package for Social Sciences (SPSS). Pain before the procedure, pain after the procedure and the pain differential on the scale were assessed as well as complications. The paired T-test was used to analyse the mean pain scores at $95 \%$ confidence interval and a p-value $<0.05$ was considered statistically significant.

\section{RESULTS}

A total of 34 patients were involved in the study. 11 males and 23 females with a male: female ratio of $1: 2.1$. The ages of the patients ranged from 20 to 80 years with a mean age of 57.2. The pathologies were disc degeneration and herniation $21(61.8 \%)$, degenerative spondylolisthesis 6 (17.5\%), spinal canal stenosis $4(11.8 \%)$ and prolapsed intervertebral disc 3 (8.8\%), Figure 1. Pain scores before the procedure: $6(17.6 \%)$ patients scored 10, $17(50 \%)$ scored 9, 9 (26.5\%) scored 8 and $2(5.9 \%)$ scored 7 on the numeric pain scale with a mean pain score of $8.8 \pm 0.81$, Table 1 . Pain scores after the procedure: $14(41.2 \%)$ of patients scored $1,9(26.5 \%)$ scored 2, 5 (14.7\%) scored 3, 4 (11.8\%) scored 4 and 1 each $(2.9 \%)$ scored 5 and 6 . With a mean pain score following the procedure being $2.2 \pm 1.34$, Table $2.28(76.5 \%)$ patients had a pain score reduction of 6 points or more, Table 3. 31 $(83.5 \%)$ of the patients had a reduction in pain score of more than $50 \%$. A statistically significant difference $(t=25.09$; $\mathrm{p}<0.000$ at $95 \%$ confidence interval) was observed between the mean pain scores before and after epidural steroid injection.

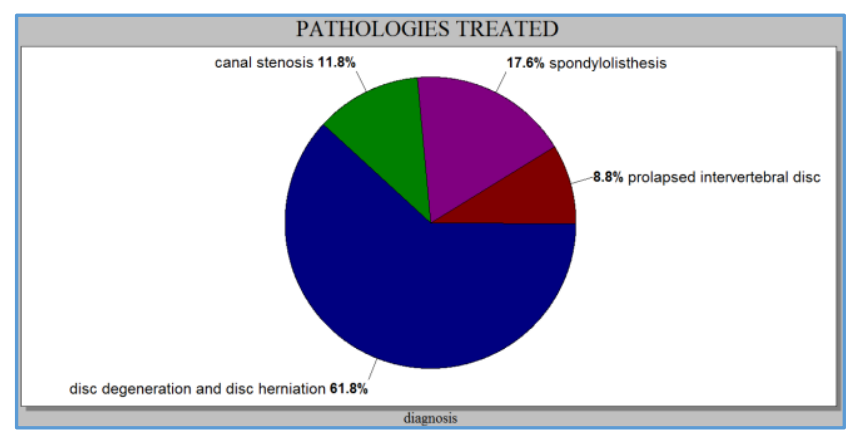

Figure 1. Pathologies treated with Epidural Steroid Injections

\begin{tabular}{|c|c|c|}
\hline Pain Score & No. of Patients & Percentage \% \\
\hline 7 & 2 & 5.9 \\
\hline 8 & 9 & 26.5 \\
\hline 9 & 17 & 50.0 \\
\hline 10 & 6 & 17.6 \\
\hline Total & $\mathbf{3 4}$ & $\mathbf{1 0 0}$ \\
\hline \multicolumn{2}{|c|}{ Table 2. Pain Scores before Epidural Steroid } \\
\hline
\end{tabular}

\begin{tabular}{|c|c|c|}
\hline Pain Score & No. of Patients & Percentage \% \\
\hline 1 & 14 & 41.2 \\
\hline 2 & 9 & 26.5 \\
\hline 3 & 5 & 14.7 \\
\hline 4 & 4 & 11.8 \\
\hline 5 & 1 & 2.9 \\
\hline 6 & 1 & 2.9 \\
\hline Total & $\mathbf{3 4}$ & $\mathbf{1 0 0}$ \\
\hline \multicolumn{2}{|c|}{ Table 3. Pain Scores after Epidural Steroid } \\
\hline
\end{tabular}

\begin{tabular}{|c|c|c|}
\hline Points of Reduction & No. of Patients & \% \\
\hline 2 & 1 & 2.9 \\
\hline 3 & 1 & 2.9 \\
\hline 4 & 3 & 8.8 \\
\hline 5 & 3 & 8.8 \\
\hline 6 & 6 & 17.6 \\
\hline 7 & 11 & 32.4 \\
\hline 8 & 5 & 14.7 \\
\hline 9 & 4 & 11.8 \\
\hline Total & $\mathbf{3 4}$ & $\mathbf{1 0 0}$ \\
\hline \multicolumn{2}{|c}{ Table 4. Degree of Reduction in Pain } \\
\hline \multicolumn{2}{|c}{} \\
\hline
\end{tabular}




\begin{tabular}{|c|c|c|c|c|}
\hline $\begin{array}{c}\text { Mean Pain } \\
\text { Score Before }\end{array}$ & $\begin{array}{c}\text { Mean Pain } \\
\text { Score After }\end{array}$ & $\begin{array}{c}\text { Paired } \\
\text { T-Test }\end{array}$ & df & P-value \\
\hline $8.8 \pm 0.81$ & $2.2 \pm 1.34$ & 25.09 & 33 & 0.000 \\
\hline Table 5. Pain Score comparison before and after Epidural \\
Steroid Injection \\
\hline
\end{tabular}

\section{DISCUSSION}

From the above study, the mean age was 57.2 years. This was similar to the age range reported by Jorgensen and colleagues(14) who had a median age of 51 years and Kobayashi et al who found an ever increasing age of degenerative diseases of the spine from 54.6 to 63.7 years over a 10-year period,(3) indicating an increasing age of this condition which may also point to the ever increasing age of populations worldwide. This further buttresses the increasing age where these pathologies present and can be ascribed to improved health care with consequent increased longevity.

The commonest condition for which epidural steroids were administered were for disc degeneration and herniation, which formed $61.9 \%$ of the patient population. The other conditions of degenerative spondylolisthesis and spinal canal stenosis were $17.6 \%$ and $11.8 \%$ respectively. The above conditions typically occur with increasing age. Prolapsed intervertebral disc only was noticed in $8.8 \%$ of the patients and this occurred amongst younger patients.

$32(94.1 \%)$ patients had a pain score of above 8 before the epidural steroid injection administration with a mean value of 8.8. Only $2(5.9 \%)$ patients had a pain score below 8 indicating great degree of discomfort before the procedure. Following the procedure, there was a marked reduction in the pain scores with $28(82.4 \%)$ patients having a pain score of 3 and below with a mean score of 2.2 following epidural steroid injection. There was a statistical difference in mean pain scores before and after epidural steroid injection. Rados et al in their study found a pain reduction by $50 \%$ or more in $53 \%$ of the patients who had epidural steroid injections.(10) In the study by Manchikanti and colleagues,(11) $86 \%$ of patients had a reduction in pain by $50 \%$ or more following epidural steroid injection.

In our study, $28(76.5 \%)$ of the patients treated with epidural steroid injection had a pain score reduction by 6 or more points with $31(85.3 \%)$ of our patients having a reduction of $50 \%$ and more in their pain scores. This shows an appreciable improvement in the pain score after epidural steroid injection.

We had no complications in our study as complications following epidural steroid injections are rare. However, complications though rare can occur and can be devastating. Examples are epidural haematoma and spinal infarction leading to paralysis as reported by some authors. $(17,18)$

\section{CONCLUSION}

Epidural steroid injections are a safe and effective method of treating patients with radiculopathy from degenerative spine diseases.

\section{REFERENCES}

[1] Hooten WM, Cohen SP. Evaluation and treatment of low back pain: a clinically focused review for primary care specialists. Mayo Clinic Proceedings 2015;90(12):1699-718.
[2] Spijker-Huiges A, Vermeulen K, Winters JC, et al. Costs and cost-effectiveness of epidural steroids for acute lumbosacral radicular syndrome in general practice: an economic evaluation alongside a pragmatic randomized control trial. Spine 2014;39(24):2007-12.

[3] Kobayashi K, Ando K, Nishida Y, et al. Epidemiological trends in spine surgery over 10 years in a multicenter database. European Spine Journal: official publication of the European Spine Society, the European Spinal Deformity Society, and the European Section of the Cervical Spine Research Society 2018: p. 1-6.

[4] Tsujimoto R, Abe Y, Arima K, et al. Prevalence of lumbar spondylosis and its association with low back pain among community-dwelling Japanese women. BMC Musculoskeletal Disorders 2016;17(1):493.

[5] Lagman C, Ugiliweneza B, Boakye M, et al. Spine surgery outcomes in elderly patients versus general adult patients in the United States: a marketscan analysis. World Neurosurgery 2017;103:780-8.

[6] Parker SL, Godil SS, Mendenhall SK, et al. Two-year comprehensive medical management of degenerative lumbar spine disease (lumbar spondylolisthesis, stenosis or disc herniation): a value analysis of cost, pain, disability and quality of life: clinical article. Journal of Neurosurgery Spine 2014;21(2):143-9.

[7] Kennedy DJ, Zheng PZ, Smuck M, et al. A minimum of 5 -year follow-up after lumbar transforaminal epidural steroid injections in patients with lumbar radicular pain due to intervertebral disc herniation. The Spine Journal: official journal of the North American Spine Society 2018;18(1):29-35.

[8] Seavey JG, Balazs GC, Steelman T, et al. The effect of preoperative lumbar epidural corticosteroid injection on postoperative infection rate in patients undergoing single-level lumbar decompression. The Spine Journal: official journal of the North American Spine Society 2017;17(9):1209-14.

[9] Okmen K, Okmen BM. The efficacy of interlaminar epidural steroid administration in multilevel intervertebral disc disease with chronic low back pain: a randomized, blinded, prospective study. The Spine Journal: official journal of the North American Spine Society 2017;17(2):168-74.

[10] Rados I, Sakic K, Fingler M, et al. Efficacy of interlaminar vs. transforaminal epidural steroid injection for the treatment of chronic unilateral radicular pain: prospective, randomized study. Pain Medicine 2011;12(9):1316-21.

[11] Manchikanti L, Singh V, Falco FJ, et al. Evaluation of the effectiveness of lumbar interlaminar epidural injections in managing chronic pain of lumbar disc herniation or radiculitis: a randomized, double-blind, controlled trial. Pain Physician 2010;13(4):343-55.

[12] Kawu AA. Epidural steroid injection in patients with lumbosacral radiculopathy in Abuja, Nigeria. Journal of Neurosciences in Rural Practice 2012;3(2):121-5.

[13] Kim EJ, Chotai S, Stonko DP, et al. Patient-reported outcomes after lumbar epidural steroid injection for degenerative spine disease in depressed versus nondepressed patients. The Spine Journal: official journal of the North American Spine Society 2017;17(4):5117. 
[14] Jorgensen SH, Ribergaard NE, Al-Kafaji OH, et al. Epidural steroid injections in the management of cervical disc herniations with radiculopathy. Scandinavian Journal of Rheumatology 2015;44(4):315-20.

[15] Klessinger S. Radicular pain in post lumbar surgery syndrome: the significance of transforaminal injection of steroids. Pain Medicine 2013;14(2):243-6.

[16] Ranguis SC, Li D, Webster AC. Perioperative epidural steroids for lumbar spine surgery in degenerative spinal disease. A review. Journal of Neurosurgery Spine 2010;13(6):745-57.
[17] Page J, Moisi M, Oskouian RJ. Lumbar epidural hematoma following interlaminar fluoroscopically guided epidural steroid injection. Regional Anesthesia and Pain Medicine 2016;41(3):402-4.

[18] Kennedy DJ, Dreyfuss P, Aprill CN, et al. Paraplegia following image-guided transforaminal lumbar spine epidural steroid injection: two case reports. Pain Medicine 2009;10(8):1389-94. 